\section{Inconsistent inheritance of telomere length (TL): is offspring TL more strongly correlated with maternal or paternal TL?}

European Journal of Human Genetics (2014) 22, 8-9; doi:10.1038/ejhg.2013.202; published online 11 September 2013

Telomeres, DNA found at the ends of chromosomes, change over the life course in response to the environment and vary across tissues. ${ }^{1,2}$ Nonetheless, the majority of variance in telomere length (TL) between close relatives is accounted for by relatedness (ie, it is highly heritable). ${ }^{3}$ The inheritance patterns of TL are characterized by two types of peculiar parental effects. First, it is now well established that paternal age at conception predicts offspring TL. ${ }^{3}$ Second, until the recent publication by Broer et al. ${ }^{3}$ in this journal, there was convincing evidence that the correlation between father and offspring blood TL is greater than the correlation between mother and offspring TL $(P=0.004$; Table 1$)$. Broer et al. ${ }^{3}$ examined fatheroffspring and mother-offspring correlations in TL across four different populations, leading to a sample size that was more than threefold larger than all previous studies combined. Their results, contrary to previous findings, showed that the mother-offspring TL correlation was substantially larger than the father-offspring correlation $(P=0.007$; Table 1$)$.

Inspired by Broer et al's ${ }^{3}$ results I have conducted a meta-analysis to estimate the mean parent-offspring correlations across all human studies and to determine whether the variability in results are likely to reflect statistical noise. These questions have important implications, including for how studies looking for the molecular genetic determinants of TL should be designed, and the response of populations to natural selection. After combining correlation coefficients across all studies no significant difference between mother-offspring and father-offspring TL correlations is evident (Table $1 ; z=-0.91$, $P=0.36$; using Fisher's $r$ to Z-transformation ${ }^{4,5}$ ). In order to quantify the difference in father-offspring versus mother-offspring correlations within each study, the correlations between motheroffspring and father-offspring pairs were transformed using Fisher's $r$ to Z-transformation ${ }^{4,5}$ and the difference taken. These difference values varied significantly across studies (randomeffects model: $\left.Q_{7}=30.67, P<0.0001\right) .{ }^{6}$ In fact, the degree of heterogeneity is considerable, with an estimated $81.5 \%$ of the variability across studies being due to heterogeneity rather than sampling error $\left(I^{2}\right.$-value $)$. This suggests that there are different mother/father correlations with offspring TL in different studies, beyond the differences expected just due to sampling noise and also calls into question the meaning of pooling average effects across all studies.

Before proceeding, I note that two studies of relevance to the question of mother/father correlations with offspring TL did not contain comparable statistical measures to allow formal inclusion in
Table 1 Summary of all previous human studies that include estimates of father-offspring and mother-offspring correlations of blood telomere length

\begin{tabular}{lrrrrrrrr}
\hline & \multicolumn{2}{c}{$\begin{array}{c}\text { Father } \\
\text { offspring }\end{array}$} & \multicolumn{2}{c}{$\begin{array}{c}\text { Mother } \\
\text { offspring }\end{array}$} & \multicolumn{2}{c}{$\begin{array}{c}\text { Mother- } \\
\text { father diff. }\end{array}$} \\
& \multicolumn{1}{c}{$n$} & \multicolumn{1}{c}{$r_{f}$} & \multicolumn{1}{c}{$n$} & $r_{m}$ & $r_{f-} r_{m}$ & $p^{a}$ & Reference \\
Northern Belgium & 81 & 0.32 & 122 & 0.52 & -0.20 & 0.097 & 15 \\
Amish in Pennsylvania & 164 & 0.46 & 168 & 0.18 & 0.28 & 0.004 & 16 \\
Northern Sweden & 42 & 0.56 & 41 & 0.16 & 0.41 & 0.036 & 12 \\
Northern Sweden & 98 & 0.45 & 129 & 0.15 & 0.31 & 0.012 & 13
\end{tabular}

Broer et al.

\begin{tabular}{|c|c|c|c|c|c|}
\hline The Netherlands & 320 & 0.29 & 407 & 0.34 & -0.05 \\
\hline UK & 501 & 0.34 & 502 & 0.48 & -0.14 \\
\hline The Netherlands & 111 & 0.49 & 110 & 0.49 & 0.00 \\
\hline Australia & 312 & 0.28 & 369 & 0.39 & -0.11 \\
\hline $\begin{array}{l}\text { mbined without } \\
\text { oer et al. }{ }^{\mathrm{b}}\end{array}$ & 385 & 0.44 & 460 & 0.27 & 0.17 \\
\hline $\begin{array}{l}\text { ombined } \\
\text { roer et al. only }\end{array}$ & 1244 & 0.33 & 1388 & 0.42 & -0.09 \\
\hline Il combined ${ }^{\mathrm{b}}$ & 1629 & 0.36 & 1848 & 0.38 & -0.03 \\
\hline
\end{tabular}

a $P$-value for difference between father-offspring and mother-offspring correlation. ${ }^{b}$ Fisher's $r$ to Z-transformation was used to combine weighted $r$-values. The mother-father difference in correlation across studies showed considerable heterogeneity $\left(Q_{7}=30.67\right.$, $P<0.0001, R=81.5 \%)$, so the pooled effects across studies should be interpreted with caution (see text for more discussion).

the above meta-analysis, but provide contrary results to those of Broer et $a .^{3}{ }^{3}$ A recent study ${ }^{7}$ reported a greater father-offspring than mother-offspring heritability in Saudi families, but did not list interpretable sample sizes or correlation coefficients. In a Filipino population, it was recently shown that not only do older fathers have offspring with longer TL, but older paternal grandfathers at the conception of father predicts longer TL in grandchildren. ${ }^{8}$ However, there was no significant association between grandchild's TL and maternal grandfathers' age at mothers' conception. This pattern might be explained by a lower heritability of TL transmitted from mothers than from fathers.

Thus, across studies there appears to be substantial unexplained heterogeneity in TL heritability patterns. Potential causes of this heterogeneity that I will briefly explore below include measurement error, publication bias, methodological variation across studies, and biological or cultural differences across populations.

Telomere length is always measured with considerable, but varying degrees of error. ${ }^{9} 10$ Might this measurement error influence heterogeneity across studies? Random measurement error attenuates the estimated association between correlated variables and thus will generally cause lower estimated parent-offspring correlations than precisely measured estimates. However, as random measurement error will on average attenuate both father-offspring and motheroffspring correlations equally, it is unlikely to explain the sometimes significantly greater father-offspring correlations and sometimes greater mother-offspring correlations. On the other hand, random measurement error could explain sometimes finding a significant difference in correlations and sometimes not. Comparable descriptive statistics of measurement error are not reported in the studies, so it is not possible to empirically asses the relationship between measurement error and outcomes.

Publication bias is known to be a widespread problem in the scientific literature. ${ }^{11}$ These biases tend to favor publishing results 
with $P$-values less than 0.05 or results that support particular theories or interests. It is possible that publication bias for 'significant' findings is a cause of the heterogeneity outlined above, although the fact that the first publication to report a greater father-offspring than motheroffspring correlation contains no formal significance test of the difference between these correlations suggests that this was not a factor in determining publication in this case. ${ }^{12}$ Also arguing against publication bias as an explanation is that whether there is greater paternal or maternal inheritance of TL does not seem to be a topic where there are vested interests in producing a particular outcome (at least from my reading of the literature).

Another potential explanation for the heterogeneity is the variation across studies in recruitment and study designs. As it has been demonstrated in one study that both father-offspring and motheroffspring TL correlations may decrease with age, ${ }^{13}$ it is possible that accounting for inter-study variation in parental ages will help explain inter-study variation. As well, paternal age predicts offspring TL, so a study population having a greater range of paternal ages might attenuate the father-offspring TL correlation. Unfortunately, neither paternal nor maternal ages are comparably reported across studies to permit evaluation of these suggestions. Other variations in studies such as the type of family cohort (ie, parent-offspring versus multigenerational), TL measurement technique or covariates included in analyses might also play a role in causing the heterogeneity in results-although particularly how this might play out is not clear.

It is also possible that the different populations from which the samples from each study were drawn from actually differ in more fundamental ways that explain the differences in parent-offspring correlations. Differences in genetics, epigenetics, environmental or cultural conditions could all be potential causes. However, all studies included in the meta-analysis (Table 1), like most genetics studies, ${ }^{14}$ were conducted within European descendant populations. There are no obvious reasons why these source populations should be expected to differ in ways that account for this heterogeneity across the narrow range of variation exhibited in these European descendant populations living in high-income countries.

Broer et al. ${ }^{3}$ provide a large well-designed examination of the paternal and maternal inheritance patterns of TL that must be taken seriously. However, when viewed together with all of the available studies of the topic (all of those studies in Table 1 plus two others that are suggestive of greater father-offspring heritability ${ }^{7,8}$ ) there is no clear conclusion that can be drawn. Some studies show stronger father-offspring correlations, some show stronger mother-offspring correlations and this is unlikely to be just statistical noise or publication bias. Instead this heterogeneity points to the importance of unobserved varying factors across studies-perhaps parental ages. While much research has understandably focused on environmental and specific molecular genetic determinants of TL, more examination of the prominent sex-specific parental effects described here could shed new light on both genetic and environmental determinants of TL.

\section{DATA SUBMISSION}

As no new data were generated or reported in this manuscript and I do not know of any appropriate public database to submit the existing data to, no data were submitted to a public database.

\section{CONFLICT OF INTEREST}

The author declares no conflict of interest.

\section{ACKNOWLEDGEMENTS}

Corinne Mar and Mark Handcock provided critical statistical assistance. Thanks to Christopher Kuzawa, Zaneta Thayer, Abraham Aviv, Darryl Holman and the two anonymous reviewers for valuable feedback and Amanda Guyton for research assistance.

\author{
Dan TA Eisenberg ${ }^{\star, 1,2}$ \\ ${ }^{1}$ Department of Anthropology, University of Washington, \\ Seattle, WA, USA; \\ ${ }^{2}$ Center for Studies in Demography and Ecology, University of \\ Washington, Seattle, WA, USA \\ E-mail:dtae@dtae.net
}

1 Eisenberg DTA: An evolutionary review of human telomere biology: the thrifty telomere hypothesis and notes on potential adaptive paternal effects. Am J Hum Biol 2011; 23: 149-167.

2 Daniali L, Benetos A, Susser E et al: Telomeres shorten at equivalent rates in somatic tissues of adults. Nat Commun 2013; 4: 1597.

3 Broer L, Codd V, Nyholt DR et al: Meta-analysis of telomere length in 19713 subjects reveals high heritability, stronger maternal inheritance and a paternal age effect. Eur $J$ Hum Genet 2013; 21: 1163-1168.

4 Strube MJ: Averaging correlation coefficients: influence of heterogeneity and set size. J Appl Psychol 1988; 73: 559-568.

5 Cohen J, Cohen P, West SG, Aiken LS: Applied Multiple Regression/Correlation Analysis For The Behavioral Sciences, 3rd edn. Mahwah, N.J.: L Erlbaum Associates, 2003.

6 Viechtbauer W: Conducting meta-analyses in $\mathrm{R}$ with the metafor Package. J Stat Software 2010; 36: 1-48.

7 Al-Attas OS, Al-Daghri NM, Alokail MS et al: Circulating leukocyte telomere length is highly heritable among families of Arab descent. BMC Med Genet 2012; 13: 38.

8 Eisenberg DT, Hayes MG, Kuzawa CW: Delayed paternal age of reproduction in humans is associated with longer telomeres across two generations of descendants. Proc Natl Acad Sci USA 2012; 109: 10251-10256.

9 Aviv A, Hunt SC, Lin J, Cao X, Kimura M, Blackburn E: Impartial comparative analysis of measurement of leukocyte telomere length/DNA content by Southern blots and qPCR. Nucleic Acids Res 2011; 39: e134.

10 Steenstrup T, Hjelmborg JV, Kark JD, Christensen K, Aviv A: The telomere lengthening conundrum-artifact or biology? Nucleic Acids Res 2013; 41: e131.

11 loannidis JP, Ntzani EE, Trikalinos TA, Contopoulos-loannidis DG: Replication validity of genetic association studies. Nat Genet 2001; 29: 306-309.

12 Nordfjäll K, Larefalk A, Lindgren P, Holmberg D, Roos G: Telomere length and heredity: Indications of paternal inheritance. Proc Natl Acad Sci 2005; 102 : 16374-16378.

13 Nordfjäll K, Svenson U, Norrback K-F, Adolfsson R, Roos G: Large-scale parent-child comparison confirms a strong paternal influence on telomere length. Eur J Hum Genet 2010; 18: 385-389.

14 Need AC, Goldstein DB: Next generation disparities in human genomics: concerns and remedies. Trends Genet 2009; 25: 489-494.

15 Nawrot TS, Staessen JA, Gardner JP, Aviv A: Telomere length and possible link to $X$ chromosome. Lancet 2004; 363: 507-510.

16 Njajou OT, Cawthon RM, Damcott CM et al: Telomere length is paternally inherited and is associated with parental lifespan. Proc NatI Acad Sci USA 2007; 104: 12135-12139. 